\title{
Protective Effect of Peanut (Arachis hypogaea L) and Its Combination with Propranolol on Dyslipidemia in Isoproterenol Induced Cardiotoxic Rats
}

\author{
Farah Naz', Nasim Jahan², Nayma Sultana ${ }^{3}$
}

\begin{abstract}
Background: Cardiotoxicity can be developed due to prolonged use of higher doses of some drugs, exposure to some chemicals, toxins or infectious agents and also by some disease conditions. Natural plant food such as peanut (Arachis hypogaea L.) may have free radical scavenging and lipid lowering activity, thereby, can be used for the prevention and management of heart disease. Objective: To observe the protective effect of peanut (Arachis hypogaea L) and its combined action with propranolol on dyslipidemia in Isoproterenol induced cardiotoxic rats. Methods: This experimental study was carried out in the Department of Physiology, Sir Salimullah Medical College (SSMC), Dhaka from January to December, 2012. Twenty Wistar albino rats, age 85-100 days, weighing 120 to $150 \mathrm{~g}$ (initial body weight) were included in the experimental group (Group B, with peanut). They were further sub-divided into group $\mathrm{B}_{1}$ (isoproterenol treated group after peanut treatment), and group $\mathrm{B}_{2}$ (isoproterenol treated group after combined treatment of peanut and propranolol). Age and weight matched 30 Wistar albino rats without any peanut supplementation was taken as control (group A) and divided into three sub-groups, group $\mathrm{A}_{1}$ (baseline control), group $\mathrm{A}_{2}$ (isoproterenol treated control) and group $\mathrm{A}_{3}$ (isoproterenol treated control after propranolol treatment). Each subgroup consisted of 10 rats. After taking final body weight all the rats were sacrificed on $22^{\text {nd }}$ day. Blood was collected from heart and supernatant serum was preserved in deep freeze until analysis. For assessment of lipid profile status, serum total cholesterol (TC), low density lipoprotein cholesterol (LDL- C) and high density lipoprotein cholesterol (HDL-C) were estimated by standard method. The statistical analysis was done by one way ANOVA and Bonferroni test as applicable. Results: In this study, percent change from initial body weight to final body weight was significantly $(p<0.01)$ lower both in isoproterenol treated group after peanut treatment and in isoproterenol treated group after combined treatment of peanut and propranolol as compared to that of baseline control. Again, this value was almost similar and the difference was not statistically significant between isoproterenol treated group after peanut treatment and isoproterenol treated group after combined treatment of peanut and propranolol. Again, the mean serum TC $(\mathrm{p}<0.01)$ and LDL-C $(\mathrm{p}<0.05)$ were significantly lower in isoproterenol treated group after peanut treatment and isoproterenol treated group after combined treatment of peanut and propranolol in comparison to those of isoproterenol treated control group. Moreover, the mean serum HDL-C was significantly $(\mathrm{p}<0.01)$ higher in isoproterenol treated group after combined treatment of peanut and propranolol, in comparison to that of isoproterenol treated control group. Furthermore, the mean serum TC and LDL-C were non significantly higher and serum HDL-C was significantly $(\mathrm{p}<0.01)$ higher in isoproterenol treated group after combined treatment of peanut and propranolol when compared to those of isoproterenol treated group after peanut treatment. Conclusion: The present study revealed that peanut alone can maintain blood lipid level by decreasing TC and LDL-C levels and by increasing HDL-C level in isoproterenol induced cardiotoxic rats. However, the combined therapy of peanut with propranolol showed synergistic effect on preventing dyslipidemia.
\end{abstract}

Key words: Peanut, Propranolol, Isoproterenol, Dyslipidemia

Bangladesh Soc Physiol. 2013, December; 8(2): 58-64 For Authors Affiliation, see end of text.

Received February 2013; Accepted October 2013 http://www.banglajol.info/index.php/JBSP 


\section{Introduction}

Cardiotoxicity is the electrophysiological dysfunction of heart and myocardial damage. ${ }^{1}$ It may be caused by chemotherapy treatment with cytotoxic drugs such as doxorubicin, epirubicin, cisplatin etc, adverse effects of heavy metals intake like lead, cadmium etc, and an incorrectly administered drug such as high dose of isoproterenol and also by some cardiotoxins. ${ }^{2}$

Coronary heart disease is the leading cause of morbidity and mortality in industrialized countries and it is emerging as a prominent public health problem in developing countries. ${ }^{3}$ While Bangladesh is turning from rural based socioeconomic structure towards urbanization, the coronary heart disease in middle aged and young group is also appearing at increasing level. ${ }^{4}$ Urbanization is characterized by a marked increase in the intake of energy dense foods, a decrease in physical activity and an increased level of psychosocial stress, all of which promote the development of diabetes, hypertension and dyslipidemia. ${ }^{5}$ All of these are the important risk factors for the development of atherosclerosis and ischemic heart disease. ${ }^{6}$

Isoproterenol is a sympathomimetic nonselective â-adrenergic receptor agonist used to produce myocardial injury in experimental animals for evaluation of various cardioprotective agents. ${ }^{7}$ High dose of isoproterenol causes severe oxidative stress in the myocardium resulting in infarction, it also generate free radicals and stimulate lipid peroxidation. ${ }^{8}$

However, propranolol is a non-selective $\beta$ blocker ${ }^{17}$ used in patients with hypertension, ischemic heart disease, cardiac arrhythmias and other cardiovascular diseases. ${ }^{9}$ But long term use of propranolol may produce dyslipidemia, bradycardia, insomnia, light-headedness etc. ${ }^{10}$

Arachis hypogaea L. known as peanut belongs to the family of fabaceae have been valued for their high nutritional content throughout the world for many years. ${ }^{11}$ Peanuts are energy dense foods that are particularly rich in fat, mostly unsaturated fatty acids and this unsaturated fatty acid of nuts through its lipid lowering effect may be responsible for their protective effects against ischemic heart disease. ${ }^{12}$ Peanuts are also a rich source of vitamin-B, vitamin-E, magnesium, copper, phosphorus, plant protein, arginine, dietary fiber and numerous bioactive substances like flavonoids, resveratrol and plant sterols. ${ }^{13}$ Peanut consumption is relatively safe but approximately $1 \%$ in the general population showed nut allergy. ${ }^{14}$

Some researchers observed that consuming about an ounce of peanuts every day can reduce the risk of heart diseases by up to half. ${ }^{15}$ Moreover some other researchers found that consumption of peanut 5 times per week (about $155 \mathrm{~g}$ of nuts/week) reduced the risk of death from coronary heart diseases by $35 \% .{ }^{16}$ Recently in a study some researchers observed that peanut oil significantly reduces LDL-cholesterol level. ${ }^{17}$ Some other researchers showed that peanut consumption may improve blood HDLcholesterol levels. ${ }^{18}$ It is well established that, dyslipidemia is one of the risk factor for the development of coronary heart disease. ${ }^{6}$

Therefore, the present study has been designed to observe the protective effect of peanut (Arachis hypogaea L) and its combined action with propranolol on dyslipidemia in Isoproterenol induced cardiotoxic rats. It is also expected that the result of this study would make peanut acceptable among the people as a rich source of nutrients with medicinal value for the prevention of coronary heart disease.

\section{Methods}

This experimental study was conducted between January and December 2012 in the Department of Physiology, Sir Salimullah Medical College (SSMC), Mitford, Dhaka. Ethical permission was taken from Institutional Ethics Committee (IEC) of SSMC. Twenty wistar albino rats, age 85-100 days, weighing 120 to $150 \mathrm{~g}$ (initial body weight) 
were included in the experimental group (Group $\mathrm{B}$, with peanut). They were further sub-divided into group $\mathrm{B}_{1}$ (isoproterenol treated group after peanut treatment), and group $B_{2}$ (isoproterenol treated group after combined treatment of peanut and propranolol). Age and weight matched 30 Wistar albino rats without any peanut supplementation was taken as control (group A) and divided into three sub-groups, group $\mathrm{A}_{1}$ (baseline control), group $A_{2}$ (isoproterenol treated control) and group $\mathrm{A}_{3}$ (isoproterenol treated control after propranolol treatment). Each subgroup consisted of 10 rats. Before grouping all the animals were acclimatized for 14 days under 12 hour dark and light cycle. During this study they had free access to food and water ad libitum. Each subgroup consisted of 10 rats and was given basal diet for 21 consecutive days. In addition to this, animals of propranolol treated control group were given propranolol $(10 \mathrm{mg} / \mathrm{kg}$ body weight; orally) for last seven (from $15^{\text {th }}$ to $21^{\text {st }}$ day of study period) consecutive days, animals of peanut treated group were given peanut extract $(500 \mathrm{mg} / \mathrm{kg}$ body weight; orally) for 21 consecutive days (started from $1^{\text {st }}$ day of study period), animals of combined treated group were given both peanut extract $(500 \mathrm{mg} / \mathrm{kg}$ body weight; orally) for 21 consecutive days (started from $1^{\text {st }}$ day of study period) and propranolol $(10 \mathrm{mg} / \mathrm{kg}$ body weight; orally) for last seven (from $15^{\text {th }}$ to $21^{\text {st }}$ day) consecutive days. All the groups of animals except baseline control group were given isoproterenol subcutaneously $(150 \mathrm{mg} / \mathrm{kg}$ body weight/day) for the last two $\left(20^{\text {th }} \& 21^{\text {st }}\right.$ day) consecutive days. After acclimatization and before giving any supplementation, body weights of all the rats were measured (initial bw). After giving isoproterenol, propranolol and peanut including the baseline control rats, were anaesthetized with the help of chloroform (30\%) and sacrificed on $22^{\text {nd }}$ day. Blood was collected from heart and supernatant serum was preserved in deep freeze until analysis. Before anaesthetized the rats their body weights (final bw) were taken. For the assessment of lipid profile status, serum total cholesterol (TC), low density lipoprotein cholesterol (LDL-C) and high density lipoprotein cholesterol (HDL-C) were measured by enzymatic method $^{19}$. All the above tests were done in the Department of Physiology, SSMC. Statistical analysis were done by one way ANOVA and Bonferroni test by using SPSS windows, version 16 .

Preparation of peanut (Arachis hypogaea L.) extract $^{20}$

Peanuts were purchased from Mohammadpur town hall market, Dhaka, dried in sunlight for 2 days and grinded in an electrical grinder. The grinded peanut $(1000 \mathrm{~g})$ was subjected to cold extraction with the use of chloroform:methanol for 7 days with frequent shaking every day. Then the extract was filtered, evaporated by using rotatory evaporator under reduced pressure. The yield of the peanut oil was $500 \mathrm{ml}$ and was fed to the experimental animals.

\section{Results}

The percent change of body weight from final to initial was significantly $(p<0.01)$ lower both in isoproterenol treated group after peanut treatment and in isoproterenol treated group after combined treatment of peanut and propranolol as compared to that of baseline control, and was almost similar and the difference was not statistically significant between isoproterenol treated group after peanut treatment and isoproterenol treated group after combined treatment of peanut(Table I).

Again, the mean serum TC $(\mathrm{p}<0.01)$ and LDL-C $(p<0.05)$ were significantly lower in isoproterenol treated group after peanut treatment and isoproterenol treated group after combined treatment of peanut and propranolol in comparison to those of isoproterenol treated control group. Moreover, the mean serum HDL$C$ was significantly $(p<0.01)$ higher in isoproterenol treated group after combined treatment of peanut and propranolol, in comparison to that of isoproterenol treated control group. Furthermore, the mean serum TC and LDL-C were non significantly higher and serum HDL-C was significantly $(\mathrm{p}<0.01)$ higher in isoproterenol treated group after combined treatment of peanut and propranolol when compared to those of isoproterenol treated group after peanut treatment (Table II). 
Table I: Body weight in different groups of rats $(\mathrm{n}=50)$

\begin{tabular}{|c|c|c|c|}
\hline \multirow[t]{2}{*}{ Groups } & \multicolumn{2}{|c|}{ Body weight (g) } & \multirow[b]{2}{*}{$\begin{array}{c}\% \text { of change } \\
\text { from final }(\mathrm{F}) \\
\text { to initial }(\mathrm{I}) \\
\text { body weight } \\
{[(\mathrm{F}-\mathrm{I}) / \mathrm{I} \times 100]}\end{array}$} \\
\hline & $\begin{array}{l}\text { Initial } \\
\text { (Day 1) }\end{array}$ & $\begin{array}{c}\text { Final } \\
(\text { Day 22) }\end{array}$ & \\
\hline $\mathrm{A}_{1}(\mathrm{n}=10)$ & $128.89 \pm 6.01$ & $137.11 \pm 6.43$ & $6.39 \pm 1.67$ \\
\hline $\mathrm{A}_{2}(\mathrm{n}=10)$ & $132.78 \pm 10.93$ & $147.83 \pm 11.06$ & $6.73 \pm 1.08$ \\
\hline $\mathrm{A}_{3}(\mathrm{n}=10)$ & $134.33 \pm 10.03$ & $152.02 \pm 10.33$ & $6.06 \pm 0.93$ \\
\hline $\mathrm{B}_{1}(\mathrm{n}=10)$ & $135.73 \pm 5.35$ & $142.63 \pm 5.45$ & $-1.64 \pm 1.07$ \\
\hline $\mathrm{B}_{2}(\mathrm{n}=10)$ & $134.44 \pm 8.08$ & $134.78 \pm 7.63$ & $-3.24 \pm 4.46$ \\
\hline \multicolumn{4}{|c|}{ Statistical analysis: } \\
\hline & \multicolumn{3}{|c|}{$\mathrm{p}$ value } \\
\hline $\mathrm{A}_{1} \mathrm{vs} \mathrm{A}_{2}$ & $0.06^{\mathrm{ns}}$ & $0.00^{* *}$ & $0.31^{\mathrm{ns}}$ \\
\hline $\mathrm{A}_{1} \mathrm{vs} \mathrm{A}_{3}$ & $0.05^{\mathrm{ns}}$ & $0.00^{* *}$ & $0.31^{\mathrm{ns}}$ \\
\hline $\mathrm{A}_{1} \mathrm{vs} \mathrm{B}_{1}$ & $0.05^{\mathrm{ns}}$ & $0.04^{*}$ & $0.00^{* *}$ \\
\hline $\mathrm{A}_{1} \mathrm{vs} \mathrm{B}_{2}$ & $0.05^{\mathrm{ns}}$ & $0.24^{\mathrm{ns}}$ & $0.00^{* *}$ \\
\hline $\mathrm{A}_{2} \mathrm{vs} \mathrm{A}_{3}$ & $0.14^{\mathrm{ns}}$ & $0.17^{\mathrm{ns}}$ & $0.09^{\mathrm{ns}}$ \\
\hline $\mathrm{A}_{2} \mathrm{vs} \mathrm{B}_{1}$ & $0.05^{\mathrm{ns}}$ & $0.16^{\mathrm{ns}}$ & $0.06^{\mathrm{ns}}$ \\
\hline $\mathrm{A}_{2} \mathrm{vs} \mathrm{B}_{2}$ & $0.35^{\mathrm{ns}}$ & $0.00^{* *}$ & $0.00^{* *}$ \\
\hline $\mathrm{A}_{3} \mathrm{vs} \mathrm{B}_{1}$ & $0.34^{\mathrm{ns}}$ & $0.02^{*}$ & $0.00^{* *}$ \\
\hline $\mathrm{A}_{3} \mathrm{vs} \mathrm{B}_{2}$ & $0.19^{\mathrm{ns}}$ & $0.00^{* *}$ & $0.00^{* *}$ \\
\hline $\mathrm{B}_{1} \mathrm{vs} \mathrm{B}_{2}$ & $0.06^{\mathrm{ns}}$ & $0.01^{* *}$ & $0.16^{\mathrm{ns}}$ \\
\hline
\end{tabular}

Data are expressed as Mean \pm SD. Statistical analysis was done by ANOVA test and then Bonferroni test was performed to compare between groups.

Group $\mathbf{A}_{\mathbf{1}}=$ Baseline control group), Group $\mathbf{A}_{\mathbf{2}}$ $=$ Isoproterenol treated control group, Group $\mathbf{A}_{\mathbf{3}}=$ Isoproterenol treated control group after propranolol treatment), Group $B_{1}=$ Isproterenol treated group afterpeanut treatment, B = Isproterenol treated group after combined treatment of peanut and propranolol. n: totalnumber of subjects., * : significant at $\mathrm{p}<0.05, \quad * *$ : significant at $\mathrm{p}<0.01$, ns: nonsignificant

61
Table II : Serum TC, LDL and HDL Levels in different groups of rats $(n=50)$

\begin{tabular}{lccc}
\hline Groups & $\begin{array}{c}\text { Serum total } \\
\text { cholesterol } \\
(\mathrm{mg} / \mathrm{dl})\end{array}$ & $\begin{array}{c}\text { Serum } \\
\text { LDL } \\
(\mathrm{mg} / \mathrm{dl})\end{array}$ & $\begin{array}{c}\text { Serum } \\
\text { HDL } \\
(\mathrm{mg} / \mathrm{dl})\end{array}$ \\
\hline $\mathrm{A}_{1}(\mathrm{n}=10)$ & $152.33 \pm 34.80$ & $113.11 \pm 36.40$ & $49.67 \pm 4.55$ \\
$\mathrm{~A}_{2}(\mathrm{n}=10)$ & $182.33 \pm 35.28$ & $130.22 \pm 32.60$ & $40.33 \pm 8.22$ \\
$\mathrm{~A}_{3}(\mathrm{n}=10)$ & $163.11 \pm 39.06$ & $109.55 \pm 32.28$ & $45.44 \pm 5.81$ \\
$\mathrm{~B}_{1}(\mathrm{n}=10)$ & $120.75 \pm 34.41$ & $87.75 \pm 29.37$ & $50.88 \pm 3.44$ \\
$\mathrm{~B}_{2}(\mathrm{n}=10)$ & $126.00 \pm 31.91$ & $89.67 \pm 26.30$ & $58.56 \pm 4.61$ \\
\hline
\end{tabular}

Statistical analysis:

\begin{tabular}{llll}
\hline & \multicolumn{3}{c}{ p value } \\
\hline $\mathrm{A}_{1}$ vs $\mathrm{A}_{2}$ & $0.04^{*}$ & $0.04^{*}$ & $0.01^{*}$ \\
$\mathrm{~A}_{1}$ vs A $_{3}$ & $0.27^{\mathrm{ns}}$ & $0.46^{\mathrm{ns}}$ & $0.05^{\mathrm{ns}}$ \\
$\mathrm{A}_{1}$ vs B & $0.04^{* *}$ & $0.48^{\mathrm{ns}}$ & $0.27^{\mathrm{ns}}$ \\
$\mathrm{A}_{1}$ vs B & $0.06^{\mathrm{ns}}$ & $0.48^{\mathrm{ns}}$ & $0.00^{* *}$ \\
$\mathrm{~A}_{2}$ vs $\mathrm{A}_{3}$ & $0.14^{\mathrm{ns}}$ & $0.10^{\mathrm{ns}}$ & $0.07^{\mathrm{ns}}$ \\
$\mathrm{A}_{2}$ vs B & $0.00^{* *}$ & $0.01^{*}$ & $0.08^{\mathrm{ns}}$ \\
$\mathrm{A}_{2}$ vs B & $0.00^{* *}$ & $0.01^{*}$ & $0.00^{* *}$ \\
$\mathrm{~A}_{3}$ vs B B & $0.02^{*}$ & $0.08^{\mathrm{ns}}$ & $0.05^{\mathrm{ns}}$ \\
$\mathrm{A}_{3} \mathrm{vs} \mathrm{B}_{2}$ & $0.02^{*}$ & $0.09^{\mathrm{ns}}$ & $0.00^{* *}$ \\
$\mathrm{~B}_{1}$ vs B B & $0.38^{\mathrm{ns}}$ & $0.45^{\mathrm{ns}}$ & $0.00^{* *}$ \\
\hline
\end{tabular}

\section{Discussion}

In the present study, the percent changes of body weight were almost similar to the findings reported by the various investigators from different countries. ${ }^{21}$

Again, in this study significantly higher levels of serum TC, LDL and lower level of HDL were observed in isoproterenol treated control group in comparison to that of baseline control group. Again, serum TC and LDL levels were significantly lower in isoproterenol treated group after peanut treatment and isoproterenol treated group after combined treatment of peanut and propranolol, but non significantly lower in isoproterenol treated control group after propranolol treatment when compared to that of isoproterenol treated control group. Whereas, serum HDL level was significantly higher in 
isoproterenol treated group after combined treatment of peanut and propranolol, but non significantly higher in isoproterenol treated control group after propranolol treatment and isoproterenol treated group after peanut treatment in comparison to that of isoproterenol treated control group. Almost similar findings were also reported by different investigators by using different herbal plants. ${ }^{8,22}$ Again, serum TC and LDL levels were almost similar, but serum HDL level was significantly higher in isoproterenol treated group after combined treatment of peanut and propranolol in comparison to that of isoproterenol treated group after peanut treatment. Similar finding was also reported by other researchers. ${ }^{23}$ On the contrary, some investigators observed reduced level of serum HDL after walnut consumption ${ }^{24}$. This discrepancy may be due to using different species of nut (walnut) in that study.

Exact lipid lowering effects of peanut and its combined action with propranolol in isoproterenol induced cardiotoxic rats are not clear. Various suggestions are proposed by different investigators. According to them, high dose of isoproterenol causes lipid peroxidation of myocardial membrane, enhanced lipid biosynthesis in the myocardium by cardiac cAMP formation, leads to myocardial necrosis, ${ }^{25}$ mobilizes lipids from adipose tissue resulting in hypercholesterolemia. ${ }^{23}$ Again, propranolol can prevent lipid peroxidation and maintain myocardial integrity ${ }^{9}$ but long term use of propranolol causes a significant decrease in HDL$\mathrm{C}$ levels and increase in LDL-C levels, ${ }^{26}$ due to the lipoprotein lipase inhibitory activity and lecithin-cholesterol acyl transferase (LCAT) lowering activity of propranolol. ${ }^{27}$ However, Oleic acid which is the predominant mono-unsaturated fatty acid in peanut prevents LDL oxidation and reduces risk of cardiovascular disease. ${ }^{17}$ The flavonoids and phytosterols of peanut show cardioprotective effect by lowering blood cholesterol levels. ${ }^{16}$ In addition to this, combined therapy of nut extract and propranolol caused synergistic cardioprotection to myocardium, by both increasing the endogenous antioxidant levels and also by scavenging free radicals. ${ }^{22}$

In the present study, dyslipidemia was observed in rats treated with isoproterenol as evidenced by higher levels of serum TC, LDL and lower level of serum HDL. This is further supported by an increase in body weight in cardiotoxic rats of present study which may be due to increased production of free radicals.

Again, lower levels of serum TC, LDL and higher level of HDL were observed in isoproterenol treated group after peanut treatment and isoproterenol treated group after combined treatment of peanut and propranolol of the present study suggested the protective effect of Peanut and its combined action with propranolol on dyslipidemia against isoproterenol induced cardiotoxicity. These effects are most likely due to mono-unsaturated fatty acid content and the free radical scavenging activity of peanut. Moreover, in this study combined therapy of peanut extract and propranolol showed synergistic effect in the improvement of dyslipidemia than when they were used alone.

\section{Conclusion}

From this study, it can be concluded that peanut alone can maintain blood lipid level by decreasing TC and LDL-C levels and by increasing HDL-C level in isoproterenol induced cardiotoxic rats. However, the combined therapy of peanut with propranolol showed synergistic effect on preventing dyslipidemia. So, combined therapy of peanut and propranolol showed synergistic cardioprotective effects by reducing the cardiovascular risk factors.

\section{Acknowledgement}

Authors of this study are thankful to Professor Dr. Sheikh Nazrul Islam, Institute of Nutrition and Food Science, University of Dhaka for the cooperation he provided. We would also express 
our sincere thanks to the DGHS for providing the partial financial support for completing the research work.

\section{Authors Affiliation}

1. *Farah Naz, Assistant Professor, Department of Physiology, Green Life Medical College, Dhaka. Email: nazf188@gmail.com.

2. Nasim Jahan, Professor \& Head, Department of Physiology, Sir Salimullah Medical College, Mitford, Dhaka. Email: prof.dr.nasimjahan@gmail.com.

3. Nayma Sultana, Associate Professor, Department of Physiology, Sir Salimullah Medical College, Mitford, Dhaka. Email: nayma_sultana@ yahoo.com.

*for correspondence

\section{References}

1. Huang C, Zhang X, Ramil JM, Rikka S, Kim L, Lee Y, Gude NA, Thistlethwaite PM. Juvenile exposure to anthracyclines impairs cardiac progenitor cell function and vascularization resulting in greater susceptibility to stress induced myocardial injury in adult mice. Circulation 2010; 121(5): 675-683.

2. Schimmel K, Richel D, Brink RVD, Guchelaar HJ. Cardiotoxicity of cytotoxic drugs. Cancer Treatment Review 2004; 30: 181-191.

3. WHO report. Neglected Global Epidemic: Three Growing Threats Shaping the Future World Health Organization. Geneva 2003; 85-99.

4. Haque MS, Baidya A, Sinha MMI. Incidence of cardiovascular diseases is of rise: a $\mathrm{DMCH}$ experience. F Dhaka Med Coll 1998; 1: 2-7.

5. Yusuf S, Reddy S, Ounpuu S, Anand S. Global Burden of Cardiovascular Disease: Part 1: General considerations, the epidemiologic transition, risk factors and impact of urbanization. Circulation 2001; 104: 2746-2753.

6. Giannattasio C, Failla M, Emanuelli G, Grappiolo A, Boffi L, Corsi D, Mancia G. Local effects of atherosclerotic plaque on arterial distensibility. Hypertension 2001; 38: 1177-1180.

7. Sushma KS, Jaydeep A, Kumar JSS. Effect of carnitine on malondialdehyde, taurine and glutathione levels in heart of rats subjected to myocardial stress by isoproterenol. Ind J Exp Biol 1989; 27: 134-137.
8. Senthilkumar H, Anandan R, Devaki T, Santhoshkumar M. Cardioprotective effects of Picrorrhiza kurrora against isoproterenol induced myocardial stress in rats. Fitoterapia 2001; 72: 402-405.

9. Asdaq SMB, Inamdar MN. Pharmacodynamic andpharmacokinetic interactions of propranolol with Garlic (Allium sativum) in rats. Evi Based Com\& Alt Med 2011; 11.

10. Hoffman BB. Adrenoceptor antagonist drugs in Katzung BG. Basic and Clinical Pharmacology. $8^{\text {th }}$ ed. The McGraw Hill Companiesz: Amarica 2001; 138-152.

11. Higgs J. The beneficial role of peanuts in the dietpart 2. Nutr \& Food Sci 2003; 33(2): 56-64.

12. Sabate J. Does nut consumption protect against ischemic heart disease?. Eur J Clinl Nutr1993; 47(1): S71-S75.

13. Griel AE, Eissenstat B, Juturu V, Hsieh G, KrisEtherton PM. Improved diet quality with peanut consumption. J Am Coll Nutr 2004; 23(6): 660668.

14. Crespo JF, James JM, Fernandez-Rodriguez C, Rodriguez J. Food allergy: nuts and tree nuts. Br J Nutr 2006; 96: 95-102.

15. Fraser GE, Sabate J, Beeson WL, Strahan TM. A possible protective effect of nut consumption on risk of CHD. Arc Int Med 1992; 152: 1416-1424.

16. Hu FB, Stampfer MJ, Manson JE, Rimm EB, Colditz GA, Rosner BA, Speizer FE, Hennekens CH, Willett WC. Frequent nut consumption and risk of coronary heart disease in women: prospective cohort study. Brit Med J 1998; 317: 1341-1345.

17. Sales RL, Coelho SB, Costa NMB, Bressan J, Iyer S, Boateng LA, Lokko P, Mattes RD. The effect of peanut oil on lipid profile of normolipidemic adults: a three country collaborative study. J Appl Res 2008; 8(3): 216-225.

18. Emekli-Alturfan E, Kasikci E, Yarat A. Peanuts improve blood glutathione, HDL-cholesterol level and change tissue factor activity in rats fed a high cholesterol diet. Eur J Nutr 2007; 46: 476-482.

19. Allain CC, Poon LS, Chan CS, Richmond W, Fu PC. National Cholesterol Education Program (NCEP) recommended values for cholesterol. Clin Chem 1974; 20: 470. 
20. Williams SW 1984, Standard Official Methods of Analysis, in Association of Analytic Chemists (AOAC), $14^{\text {th }}$ ed, Washington DC.

21. Chakraborty M, Asdaq SMB. Interaction of Semecarpus anacardium L. with propranolol against isoproterenol induced myocardial damage in rats. Ind J Exp Biol 2011; 49: 200-206.

22. Subhash KSV, Kumar TK, Chidambranathan N, Prabhu V. Phytochemical analysis and cardioprotective activity of Plunbago zeylanica Linn in isoproterenol provoked oxidative myocardial injury in albino Wistar rats. Int Res $\mathrm{J}$ Pharm 2012; 3(9): 226-230.

23. Asdaq SMB, Inamdar MN, Asdaq M. Effect of conventional antihypertensive drugs on hypolipidemic action of garlic in rats. Ind $\mathrm{J}$ Exp Biol 2009; 47: 176-181.
24. Ros E, Nunez I, Perez-Heras A, Serra M, Gilabert R, Casals E, Deulofeu R. A walnut diet improves endothelial function in hypercholesterolemic subjects: a randomized crossover trail. Circulation 2004; 109: 1609-1614.

25. Paritha I, Devi SCS. Effect of tocopherol on lipid peroxidation in isoproterenol induced myocardial infarction in rats. Ind J Physiol Pharmacol 1997; 41: 369 .

26. Roman O, Pino ME, Pereda T, Valenzuela A. Effects of pindolol and propranolol on blood lipids in hypertensive patients. Cardiovascular Drugs and Therapy 1989; 3: 767-770.

27. Greenberg G, Brennan PJ, Miall NE. Effects of diuretics and beta-blocker therapy in the Medical Research Council trial. Am J Med 1984; 76: 45-51. 